\title{
Pharmacy cases in Second Life: an elective course
}

This article was published in the following Dove Press journal:

Advances in Medical Education and Practice

10 October 2012

Number of times this article has been viewed

\section{Michael A Veronin ${ }^{1,2}$ \\ Lacy Daniels ${ }^{1,2}$ \\ Elaine Demps ${ }^{2}$}

'Department of Pharmaceutical Sciences, Texas A\&M Health Science Center, Kingsville, TX, ${ }^{2}$ Irma Lerma Rangel College of Pharmacy, Texas A\&M Health Science Center, Kingsville, TX, USA
Correspondence: Michael A Veronin Department of Pharmaceutical Sciences, Irma Lerma Rangel College of Pharmacy,

Texas A\&M Health Science Center,

MSC I3I, 1010 West Avenue B, Kingsville,

TX, 78363-8202, USA

Tel + I 36| 22I 0755

Fax + I 36I 5934303

Email veronin@tamhsc.edu
Abstract: Interactive pharmacy case studies are an essential component of the pharmacy curriculum. We recently developed an elective course at the Rangel College of Pharmacy in pharmacy case studies for second- and third-year Doctor of Pharmacy students using Second Life $^{\circledR}$ (SL), an interactive three-dimensional virtual environment that simulates the real world. This course explored the use of SL for education and training in pharmacy, emphasizing a case-based approach. Virtual worlds such as SL promote inquiry-based learning and conceptual understanding, and can potentially develop problem-solving skills in pharmacy students. Students were presented ten case scenarios that primarily focused on drug safety and effective communication with patients. Avatars, representing instructors and students, reviewed case scenarios during sessions in a virtual classroom. Individually and in teams, students participated in active-learning activities modeling both the pharmacist's and patient's roles. Student performance and learning were assessed based on SL class participation, activities, assignments, and two formal, essay-type online exams in Blackboard 9. Student course-evaluation results indicated favorable perceptions of content and delivery. Student comments included an enhanced appreciation of practical issues in pharmacy practice, flexibility of attendance, and an increased ability to focus on course content. Excellent student participation and performance in weekly active-learning activities translated into positive performance on subsequent formal assessments. Students were actively engaged and exposed to topics pertinent to pharmacy practice that were not covered in the required pharmacy curriculum. The multiple active-learning assignments were successful in increasing students' knowledge, and provided additional practice in building the communication skills beneficial for students preparing for experiential clinical rotations.

Keywords: Second Life, virtual worlds, pharmacy case studies, computer simulation, health education, pharmacy education

\section{Introduction}

Interactive case studies are an essential component of education and training in schools of medicine, pharmacy, nursing, and allied health. The case study approach is a proven way in which active learning strategies can be implemented. Case studies shift the emphasis from "teacher-centered" to more "student-centered" activities, and can be conducted with groups of students, or individually. ${ }^{1}$ At the Rangel College of Pharmacy, case studies are conducted in live, interactive group sessions between faculty members who facilitate the classroom sessions and students. With typical class sizes of about 85 to 90 students, the sessions often require substantial institutional resources and a substantial time commitment for successful implementation. 
In this paper, we describe an elective course recently developed at the Rangel College of Pharmacy that offers a unique approach to the presentation of case studies through computer-simulation exercises delivered via Second Life ${ }^{\circledR}$ (SL). ${ }^{2} \mathrm{SL}$ is a virtual world with great promise in education, but relatively little is known of its effectiveness in teaching pharmacy students.

Introduced on June 23, 2003, SL is an online, threedimensional computer-generated environment that simulates the real world. ${ }^{2}$ With SL, the computer end user logs on to the program and becomes a "resident" by creating a customdesigned avatar (a representation of oneself) to navigate in the virtual world. An individual's avatar can be a person, character, or even an animal or icon. ${ }^{3}$ An individual can interact and communicate with others via their avatars and travel to a variety of locations in a variety of ways, such as walking, running, and even flying and teleportation. Interaction can take place on public land or within restricted areas, such as islands that can be closed to the public. Islands may be created for a specific purpose, such as business, political, or educational use. ${ }^{4}$

According to the Accreditation Council for Pharmacy Education (ACPE), "The development of critical thinking and problem-solving skills through active learning strategies and other high level pedagogical strategies should be supported throughout the curriculum. Active learning strategies include the application of computer and other instructional technologies, laboratory experiences, case studies, guided group discussions, simulations, and other practice-based exercises" (standard 11, guideline 11.2). ${ }^{5}$

Simulation is not a concept that is new to pharmacy education. Patient simulators have been used to simulate direct patient care in such areas as cardiovascular pharmacotherapy and advanced cardiovascular life support, and in pharmacotherapy and clinical assessment courses. ${ }^{6}$

Virtual simulation and pharmacy education is in its infancy. Although the potential of SL for health-profession education has been demonstrated, ${ }^{7}$ literature searches reveal a limited number of formal applications of SL for this purpose, and minimal evaluation of educational outcomes. ${ }^{8}$ If active learning can occur with simulation in a virtual world such as SL, then pharmacy education should begin to address how this technology can support the curriculum and provide effective teaching and learning. The development of this elective course provides a step in this direction.

\section{Educational environment}

The Rangel College of Pharmacy is part of the Texas A\&M Health Science Center but is located on the campus of
Texas A\&M University-Kingsville in Kingsville, Texas, and offers a traditional 4-year Doctor of Pharmacy program. Preclinical teaching and learning take up a majority of classroom and laboratory time in the first three years of the pharmacy curriculum as students prepare for entering fulltime Advanced Pharmacy Practice Experiences (APPEs) in their final year. At the Rangel College of Pharmacy, students are allowed to begin taking elective courses in the spring semester of the second year, and they continue taking electives in the third year. The SL course was offered to all third-year pharmacy students in the Fall 2010 semester, and again to third-year, as well as second-year, students entering their fourth semester in Spring 2011.

Technology is a significant part of the students' educational experience. The College of Pharmacy (COP) requires students to purchase a laptop computer that has been certified as meeting all necessary requirements to complete College of Pharmacy course work. The students use their laptops extensively, accessing course content in Blackboard Learn ${ }^{\mathrm{TM}}$ (Blackboard Inc, Washington, DC), and submitting course assignments. The students' laptops are the primary mode for accessing and attending classes in SL.

In addition, the Rangel COP has a student computer laboratory with 40 computers available for students. In our course, students were required to meet in this laboratory for the major assessments.

\section{Course description}

For both semesters, the SL elective course had an enrollment of twelve students per semester. The elective course was offered for one credit hour and met for 50 minutes, one day per week for 15 weeks. Overall, twenty-three students completed the elective course, with one student unable to complete the course requirements in the fall of 2010. The faculty assigned students to their respective groups, which generally included four students per group.

Each session was facilitated by two pharmacy faculty members and the Director of Instructional Technology. The two pharmacy faculty members shared equal responsibility for course content and activities and supervised the pharmacy students during class sessions. Frequently, other faculty or staff members joined the class as patient actors or observers. Each student was able to access the SL site with a personal laptop computer or a desktop computer in the school's computing center.

The semester schedule included one session for course introduction, one session touring relevant locations in SL, ten sessions of case study presentations and discussions, 
one session for a review of the topics, and two examination periods. All class meetings were held in SL, with the exception of examinations.

\section{Design}

Each SL session was carried out using the tools available from Linden Lab, the maker of SL. ${ }^{2}$ The viewer software is available free of charge by accessing the site, and following the guidelines explained on the site.

Preparation for the elective experience required several planning meetings of faculty and staff members prior to the implementation. The development of avatars, pilot testing, and the training of faculty and staff facilitators required approximately 4 to 6 hours of faculty time. At the beginning of the course, all students had been instructed in the fundamentals of using SL in a series of practical exercises. Students downloaded the software program and created their own custom avatars. Students then performed a maneuverability and navigation assignment with their avatars.

For class sessions, students were required to meet at predetermined sites in SL. Most class meetings were held at the Rangel College of Pharmacy's virtual pharmacy school site. The site simulates the actual College of Pharmacy building, with two floors to accommodate several avatars and multiple places to meet. On the first floor is a large reception room with several desks and chairs. On the second floor is a large conference room with a large table and chairs to accommodate meetings. With the use of headphones and a microphone, students had the opportunity to hear and converse with other avatars in the learning environment, or alternatively, text could be used to communicate with the group or with individuals, with words appearing in boxes on the computer screen (Figure 1). In addition to communicating among themselves, instructors and/or SL residents volunteering as patient actors were able to ask questions or present problems to students. Student pharmacist/patient role play, which has historically been conducted between students in real classrooms, was facilitated in the class sessions. Avatars representing patients can be personalized by instructors, thus giving students' avatars more opportunity to focus on their role as practitioner.

Within each class period, students were presented a specific clinical situation, and were required to resolve the major problem and its components collectively, working in small groups.

A typical class began when all students met in a large group and were presented with a case scenario. The scenario often took the form of a dialog between avatars, or of a faculty



Figure I Class meeting of pharmacy case studies in April, 20 I I.

Notes: A typical virtual classroom in Second Life ${ }^{\circledR}$ with participants. Seated in a circle are avatars that represent students and instructors who are able to communicate in discussions via microphone or textbox.

member describing the facts of the case. The information from the case was also presented on a notecard and sent to small group leaders to distribute to members of their group. Each class period consisted of approximately 15 minutes of presentation of a clinical scenario, followed by 20 minutes of a group breakout session where students met in small groups of four, to review the facts of the case and to formulate appropriate solutions to the problems in the case. The remainder of the class period (approximately 15 minutes) was spent with a designated group leader presenting the solutions of the case to the rest of the class.

During the discussion of the case, the students were required to record information on notecards, using the notecard feature of SL. After the discussion, students met as a whole again to share their responses among the group members. Questions were presented to students in openended format; a major skill to be developed in students was to formulate answers to these types of questions. To assist with answering questions, students used information-seeking skills previously learned with traditional drug-information references. After students identified and located information for clinical questions, the course focused on how to evaluate the data for relevance, validity, and clinical application. With feedback from fellow students, students learned how to identify clinical significance and compare therapies. A typical case with questions is presented in the Supplementary Data.

The goal of each session was for students to acquire new knowledge and skills in a unique manner, unlike other 
methods currently utilized in the curriculum. In addition, students were introduced to practical solutions to clinical problems drawn from real-life incidents.

\section{Course content}

Prior to the elective, students had completed several integrated pharmacotherapy courses, and to some degree, students had been exposed to the clinical topics covered in the elective course. A major aim of the SL elective is to augment pharmacotherapy knowledge with patient verbal-communication skills; another is to address practical pharmacy-practice issues related to topics covered in the required didactic curriculum. The approach used can be described as modified self-directed learning. ${ }^{9}$ A major focus of the course is to help students develop the strategies and thought processes necessary to becoming lifelong learners and prepare for clinical practice in APPEs, residency, and/or employment. The broad objectives of the course are to improve student problem-solving, interview, and all-round communication skills, to help students learn or reinforce a variety of concepts and facts about medications, especially regarding drug overdose or misuse issues, and to develop methods for the effective use of SL in pharmacy education. Table 1 presents the overall course objectives.

A variety of scenarios was presented throughout the semester, which covered many topics using a consistent active-learning teaching method (Table 2). In particular, the students participated in a series of overdose and infectiousdisease case discussions in an SL classroom. Incorporation of this virtual three-dimensional simulation into the curriculum for pharmacy students provided for the integration of information-seeking and communication skills, both written and verbal.

Table I Course learning objectives for PHAR 789 (Pharmacy Case Studies in Second Life: An Elective Course), as presented in the syllabus

I. Evaluate pharmacy cases to develop skills in recognizing and resolving medication-related problems.

2. Interpret and apply evidence-based information to improve patient health outcomes.

3. Enhance and refine clinical problem-solving and critical thinking skills in a pharmacy setting.

4. Refine written communication skills in response to questions regarding drug therapy primarily involving infectious disease, drug overdose, and drug interactions.

5. Identify key areas of knowledge on specific infectious disease and drug therapy issues.

6. Develop proficiency in navigating and performing operations in the virtual environment of Second Life.
Table 2 Course topics for PHAR 789 (Pharmacy Case Studies in Second Life: An Elective Course)

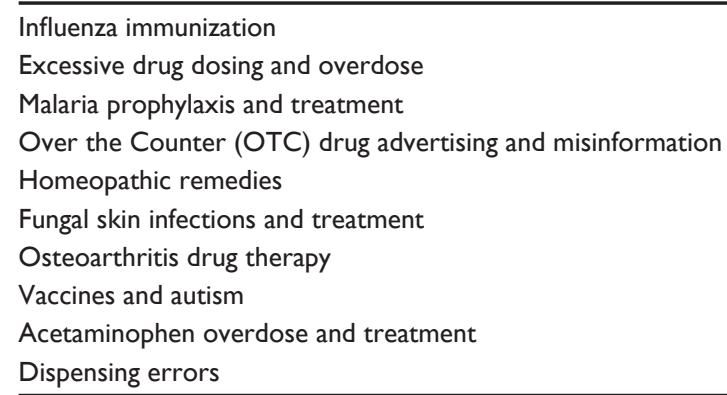

For example, in one session, students were posed the question, "Do vaccines cause autism?" To explore this question, a case was presented to students about a young mother who asked the pharmacist about the risks involved with vaccinating her 5-year-old, and specifically the risk of acquiring autism (Supplementary data). When students explored therapeutic issues such as this, or compared therapy options, each student was asked to relate this information to experiences from an introductory pharmacy practice experience or internship to share with the class.

\section{Assessments}

During each semester, two different methods of assessment were utilized: (1) written in-class assignments for each group evaluated by faculty members at the end of each class period and (2) individual major assessments conducted twice during the semester.

For the in-class assignments, students were provided questions at the beginning of class and were awarded a certain number of points for their responses provided on notecards to the questions on the case. The points generally ranged from 5 to 10 points per assignment. Students within each small group collaborated during the breakout sessions in each class period to formulate their best responses to questions. Students were required to place their responses to the questions on small-group notecards in SL, and turn in the cards to a course instructor at the end of class. Students regularly excelled in using search tools and resources, such as Drugs.com, to identify relevant information regarding the clinical questions. The point totals for the assignments contributed to $40 \%$ of the student's end-of-semester grade.

In addition to the in-class assignment, for the spring 2011 semester, students were given a take-home writing assignment, to assess their writing skills and to let them view the level of detail needed for a complete response to a written short-answer question. The grading criteria were outlined in 
a rubric: answering the questions completely, evaluating the information contained in the answers, providing an evidencebased answer, identifying the best solution from more than one option, and overall organization. The point total for the writing assignment contributed to $7 \%$ of the student's endof-semester grade.

To assess overall knowledge and skills, students were given two cumulative examinations, a midterm and a final at weeks 8 and 15, respectively. The exams made up approximately half of the student's final grade (53\%), and consisted of 15 to 20 questions in open-ended, short-answer format. The exams were graded by the course faculty members, and the grading rubric was shared with students. For the 2010 fall semester, exam grades ranged from $67.7 \%$ to $94.9 \%$ (mean: 89.5\%); the Spring 2011 exam grades ranged from 83.3\% to $94.8 \%$ (mean: $91.1 \%$ ). Students most often lost points for formulating an incomplete or poorly structured response to a question or for not identifying or prioritizing relevant issues based on their initial clinical question.

\section{Student feedback}

At the end of the course, students were given the standard end-of-semester course evaluation, used for all course evaluations, for feedback on the course (Table 3 ). The evaluation included a list of questions and asked the students to identify strengths and weaknesses of the course. Additionally, upon completion of the elective course, a survey on the students' overall impression of the course, with likes and dislikes, was administered. The survey was developed by the course instructors for the purpose of this elective and had not been previously validated.

The most notable feedback was observed in students' comfort and familiarity with using SL as a communication medium.
Students appreciated the ability to log on and view the course proceedings away from the "fixed" site of the school campus. When students were asked to assess their comfort with this environment, most felt it was better than video, but still preferred a live session. All students felt the unique environment was conducive to learning.

A major limitation of the evaluation of the course was the low sample size (about 50\% response rate), which made it difficult to extrapolate this information to an entire class, curriculum, or other schools of pharmacy. With further course offerings, we hope to have more results to help in our evaluations.

\section{Discussion}

Faculty members may be familiar with SL, and social networking in general; however, it remains to be seen whether these tools will be fully accepted as part of a pharmacy curriculum. With this elective course, we have demonstrated that the use of SL for course delivery has significant potential in pharmacy education.

While the conventional approach to case studies affords the opportunity for students to problem-solve and make relevant clinical decisions, at the Rangel College of Pharmacy, case studies are often conducted in large classes, which can limit students' personal involvement and participation. Also, the exercises can be laborious for faculty to produce, and can become redundant and outdated quickly. SL was used in a flexible standardized format for case studies and was made available to students anywhere a laptop was available, with minimal development, training, and hardware.

Some concerns may exist over the use of SL for course delivery. One apprehension is the risk of students being less proficient than with live verbal and written

Table 3 Student feedback for PHAR 789 (Pharmacy Case Studies in Second Life: An Elective Course), Fall 2010 and Spring 201 I semesters

\begin{tabular}{|c|c|c|c|c|c|c|c|c|c|c|c|}
\hline & & \multicolumn{10}{|c|}{ Responses } \\
\hline & & SA & A & $\mathbf{N}$ & $\mathbf{D}$ & SD & Med & Mode & STDV & $\mathbf{n}$ & Mean \\
\hline \multicolumn{12}{|c|}{ Course evaluation student responses, Fall 2010} \\
\hline \multicolumn{12}{|c|}{ College-wide questions } \\
\hline Q। & The stated objectives of this course were consistently pursued. & 4 & 2 & 0 & 0 & 0 & 5 & 5 & 0.47 & 6 & 4.67 \\
\hline Q2 & The grading system was clearly explained. & 2 & 3 & I & 0 & 0 & 4 & 4 & 0.69 & 6 & 4.17 \\
\hline Q3 & Attendance in this class was essential to good learning. & 5 & I & 0 & 0 & 0 & 5 & 5 & 0.37 & 6 & 4.83 \\
\hline Q4 & Web based handouts were valuable supplements to this course. & 2 & 3 & 0 & 0 & 0 & 4 & 4 & 0.49 & 5 & 4.40 \\
\hline Q5 & This course contributed significantly to my professional growth. & 5 & I & 0 & 0 & 0 & 5 & 5 & 0.37 & 6 & 4.83 \\
\hline Q6 & I am generally pleased with the text(s) required for this course. & 5 & 0 & 0 & 0 & 0 & 5 & 5 & 0 & 5 & 5.00 \\
\hline Q7 & The teaching methods used in this course were appropriate. & 4 & 2 & 0 & 0 & 0 & 5 & 5 & 0.47 & 6 & 4.67 \\
\hline Q8 & The facilities for this course were excellent. & 3 & 2 & I & 0 & 0 & 4.5 & 5 & 0.75 & 6 & 4.33 \\
\hline Q9 & Instruction is well coordinated among the team teachers. & 4 & 2 & 0 & 0 & 0 & 5 & 5 & 0.47 & 6 & 4.67 \\
\hline Q10 & Team teaching is effectively used in this course. & 5 & I & 0 & 0 & 0 & 5 & 5 & 0.37 & 6 & 4.83 \\
\hline
\end{tabular}

Notes: Responses received/expected: 6/12. Overall mean: 4.78.

Abbreviations: $S A$, strongly agree $=5 ; A$, agree $=4 ; N$, neutral $=3 ; D$, disagree $=2 ; S D$, strongly disagree $=1$; Med, median; STDV, standard deviation; $n$, number of subjects. 


\section{Table 4}

\section{Student comments, Fall 2010}

"This is a new medium for learning and I think that the objectives completed in the course were well executed for how new we all were to the technology. The cases were well laid out and approached for a very practical stand point which I really liked."

"I can stay home and take the class online."

"I really enjoyed this course. I hope in the future there will be more courses like this even after graduating that we can use to communicate with other professionals. The group discussions were a good way to prepare ourselves for conversations with our preceptors in our rotations."

"Certain 'rules' should be in place like: only one person should use the mic to talk at a time, all mics should be muted while the professor is speaking. This is because there is a lot of feedback and echoing when multiple people are talking. Otherwise text communication should be used."

\begin{tabular}{|c|c|c|c|c|c|c|c|c|c|c|c|}
\hline \multirow{2}{*}{\multicolumn{2}{|c|}{ College-wide questions }} & \multicolumn{10}{|c|}{ Responses } \\
\hline & & SA & $\mathbf{A}$ & $\mathbf{N}$ & D & SD & Med & Mode & STDV & $\mathbf{n}$ & Mean \\
\hline \multicolumn{12}{|c|}{ Course evaluation student responses, Spring $20 \mathrm{I} \mathrm{I}$} \\
\hline QI & The stated objectives of this course were consistently pursued. & 2 & 3 & 0 & 0 & 0 & 4 & 4 & 0.49 & 5 & 4.40 \\
\hline Q2 & The grading system was clearly explained. & I & 3 & I & 0 & 0 & 4 & 4 & 0.63 & 5 & 4.00 \\
\hline Q3 & Attendance in this class was essential to good learning. & 3 & 2 & 0 & 0 & 0 & 5 & 5 & 0.49 & 5 & 4.60 \\
\hline Q4 & Web-based handouts were valuable supplements to this course. & 2 & I & 2 & 0 & 0 & 4 & 3,5 & 0.89 & 5 & 4.00 \\
\hline Q5 & This course contributed significantly to my professional growth. & I & 4 & 0 & 0 & 0 & 4 & 4 & 0.40 & 5 & 4.20 \\
\hline Q6 & I am generally pleased with the text(s) required for this course. & I & I & I & 0 & 0 & 4 & $3,4,5$ & 0.82 & 3 & 4.00 \\
\hline Q7 & The teaching methods used in this course were appropriate. & 2 & 3 & 0 & 0 & 0 & 4 & 4 & 0.49 & 5 & 4.40 \\
\hline Q8 & The facilities for this course were excellent. & I & 4 & 0 & 0 & 0 & 4 & 4 & 0.40 & 5 & 4.20 \\
\hline Q9 & Instruction is well-coordinated among the team teachers. & 2 & 3 & 0 & 0 & 0 & 4 & 4 & 0.49 & 5 & 4.40 \\
\hline Q10 & Team teaching is effectively used in this course. & 2 & 3 & 0 & 0 & 0 & 4 & 4 & 0.49 & 5 & 4.40 \\
\hline
\end{tabular}

\section{Student comments, Spring $201 \mathrm{I}$}

"I really liked the free response assignments and exams. The class was very interactive and a lot of fun."

"I enjoyed the fact that we learned information that will be useful in practice that was lacking in our education thus far."

"Sometimes there were difficulties when trying to communicate in Second Life."

"The grading was a bit confusing. There were a couple questions on exams that may have had points taken off needlessly but it wasn't enough to be worth questioning."

"We seemed to run over time more often than not which did not please me. However I enjoyed the class and learned a lot. Also I enjoyed the laid back atmosphere."

Notes: Responses Received/Expected: 5/I2. Overall Mean: 4.44.

Abbreviations: $S A$, strongly agree $=5 ; A$, agree $=4 \mathrm{~N}$, neutral $=3 ; \mathrm{D}$, disagree $=2 ; \mathrm{SD}$, strongly disagree $=1$; STDV, standard deviation; $\mathrm{n}$, number of subjects.

communication skills. In general, educators are concerned that the use of technology and online learning environments "may not give the immediacy that is required for successful social interaction." 10 Our experience did not support this notion, and SL actually provided an additional option for collaboration, interaction, and presentation of information. Faculty members and other stakeholders in pharmacy education also may be hesitant to adopt SL because it could be viewed in the same light as online coursework - as a "shortcut" with regard to presenting course information and lacking the opportunity for active learning. SL is not meant to replace in-class teaching, but offers an alternative to faceto-face interaction. In our experience, the skills of identifying, retrieving, and evaluating medical and drug information are not changed by SL, because these are essential for all clinicians and lifelong learners. With case studies, students are still expected to focus primarily on course content, conduct appropriate information searches, and evaluate the case information.
In addition to case studies, there are a virtually unlimited number of applied uses for this technology. Guest lecturers have been invited to participate in discussions, and faculty members and students have toured other SL virtual islands to view new environments. Faculty and student professional associations can meet, and students can collaborate with other pharmacy students or students studying in other health disciplines within the health science center or even from around the world. In the future, we anticipate using more-elaborate scenes, scenarios, and props with experienced patient actors, enhancing the feeling of reality and the learning experience.

The use of SL in a pharmacy curriculum will require some adaptations. SL can be considered a specific type of online distance learning. In general, the successful implementation of distance-learning strategies must include adequate instructional-design support and faculty-development programs. ${ }^{11}$ An essential element of success in teaching with SL includes faculty members who are willing to take on new instructional 
challenges and have the cooperation and support of their institution, which includes commitment from instructional technology components for faculty education and training.

At this point in the development of SL, the refined interactive components such as facial expression, subtle gestures, and other visual cues are not present and to some degree inhibit effective nonverbal communication among participants. As technology continues to improve with SL, and faculty experience increases, it is anticipated that this aspect of the program will be improved upon.

Although not prohibitive, another potential hindrance to widespread adoption of SL is the issue of start-up and maintenance costs. If SL is used for a large-scale audience, the expense of developing an SL site (such as buildings, or a region or island) may not be as great as duplication of effort for individual projects. In considering start-up costs, the use of SL may be more cost-effective in the long run than redesigning highly technical virtual-learning tools every time the need arises. ${ }^{12}$ Ultimately, small classes can easily be carried out in free "public spaces" in SL, although this may not be preferable in all cases.

The Rangel College of Pharmacy uses competency-based educational approaches in both preclinical and clinical assessments. Students are expected to exhibit certain skills and behaviors at predetermined levels of competence in preparation for APPE requirements and, ultimately, in order to establish their eligibility for the North American Pharmacist Licensure Examination, upon graduation. Since its inception in 2006, the Rangel College of Pharmacy has used a variety of technological innovations for course delivery in working towards these goals. It is our desire that the course be beneficial in preparing students for APPEs and future pharmacy practice. Our informal impressions are that students had gained confidence and were more comfortable understanding real-life clinical issues. One student in the elective stated, "Real-world cases are a nice change of pace from the classroom." At the Rangel College of Pharmacy, the elective course will continue to be offered to second-year and third-year students.

\section{Conclusion}

SL is a work in progress, yet in its current form, it can be an effective way to deliver course materials in a pharmacy program. Based on our experiences, SL offers significant advantages to other types of distance-learning technologies in that it is relatively cost effective in building many simulations, offers capabilities for real-time role-playing, and as this course has demonstrated, can provide a way to creatively explore critical thinking. For students who may desire less time sitting in the classroom, SL offers a means of allowing students to move around and interact in a novel learning environment. Simulations within SL can enhance learning by engaging students in interactive dialog, which can take place from any campus or computer.

SL can also advance collaboration of virtual communities in health care from around the world. ${ }^{13}$ Practitioners can access communities of practitioners in the virtual worlds of SL to meet formally or informally to share best practices and advice. In the not-too-distant future, it may be commonplace for pharmacists, pharmacy students, and other health care practitioners to share innovations and participate in professional activities in SL, along with millions of users around the world.

\section{Disclosure}

The authors report no conflicts of interest in this work.

\section{References}

1. Davis C, Wilcock E; UK Centre for Materials Education. Teaching Materials Using Case Studies [Web page document on the Internet]. http://www.materials.ac.uk/guides/casestudies.asp. Accessed June 22, 2012.

2. SecondLife.com [webpage on the Internet]. Linden Research Inc;2003; v 2.0. http://secondlife.com. Accessed June 15, 2012.

3. Second Life Wiki. Private Region [Web page on the Internet]. http:// wiki.secondlife.com/wiki/Private_Island. Accessed June 27, 2012.

4. Skiba DJ. Nursing education 2.0: Second Life. Nurs Educ Perspect. 2007;28(3):156-157.

5. Accreditation Council for Pharmacy Education. Accreditation Standards and Guidelines: Professional Program in Pharmacy Leading to the Doctor of Pharmacy Degree [Web page on the Internet]. Chicago, IL: Accreditation Council for Pharmacy Education; January 1, 2009. http://www.acpe-accredit.org/standards/default.asp. Accessed June 15, 2012.

6. Shrader S, McRae L, King W, Kern D. A simulated interprofessional rounding experience in a clinical assessment course. Am J Pharm Educ. 2011;75(4):Article 61

7. Kramer GA, Albino JEN, Andrieu SC, et al. Dental student assessment toolbox. J Dent Educ. 2009;73(1):12-35.

8. Wiecha J, Heyden R, Sternthal E, Merialdi M. Learning in a virtual world: experience with using Second Life for medical education. $J$ Med Internet Res. 2010;12(1):e1.

9. Murad MH, Varkey P. Self-directed learning in health professions education. Ann Acad Med Singapore. 2008;37(7):580-590.

10. McInnerney JM, Roberts TS. Online learning: social interaction and the creation of a sense of community. Educational Technology and Society. 2004;7(3):73-81.

11. Andrews KG, Demps EL. Distance education in the US and Canadian undergraduate dental curriculum. J Dent Educ. 2003;67(4): $427-438$.

12. Stott D. Learning the second way. Br Med J. 2007;335:1122-1123.

13. Wordpress.com. Imperial College Islands: Second Health London [Web page on the Internet]. http://secondhealth.wordpress.com/ imperial112college-islands/. Accessed June 22, 2012. 


\section{Supplementary data}

Example of case study session in the Second Life elective course

Title of case: "Do vaccines cause autism?"

\section{Case summary}

You are the pharmacist-intern at Community Pharmacy in Corpus Christi. A regular customer/patient of yours approaches the pharmacist one day with a question about vaccinations.

Your customer is a mother of a 5-year-old boy about to start kindergarten, and she tells the pharmacist that she received a note from the school nurse stating that she needs to provide vaccination records for the child. She has heard a lot in the news about autism and vaccines. The mother says that when her child was a baby, he received all of the "shots," but now she doesn't want her child to have any more because "he might come down with autism."

Since you are a pharmacist intern working with the pharmacist, what advice can you give? What are the potential risks involved? What course of action should be followed to remedy the situation?

\section{Assignment criteria for the students}

Research the facts of the case and provide answers to the following questions:

1. Which vaccine or vaccines are linked to autism in children?

2. What is the agent in the vaccine that may be the likely cause of autism? What is the strength of the evidence for the "cause and effect" relationship?

3. What information should you provide the patient? (In this case, the patient's mother).

\section{Dialog between patient actor and pharmacist-instructor to introduce the case session to students}

Pharmacist: How can I help you?

Patient: Hi, I could use some good advice with a situation I have at my son's school. He's almost 5 years old, and is going to start kindergarten soon, and before he starts, I need to give the school nurse his shot records. They won't let him start school until I give them his records.

Pharmacist: We don't provide vaccinations for infants here at this pharmacy, so we would not have your son's records. Have you checked with your doctor about getting copies of the records?

Patient: That's not really the problem. When he was a baby, he got all of the shots that he needed when he had his check-ups. But now, I've heard a lot of bad things about vaccines and autism, and I'm afraid to give him any more shots, because he might come down with autism.

Pharmacist: So you haven't updated your vaccinations with your son since he was a baby?

Patient: That's right, and I wonder if you can tell me if there is anything I can do or any shot that I can give him that won't cause autism. If you can help me out, I'd be very grateful.
Advances in Medical Education and Practice

\section{Publish your work in this journal}

Advances in Medical Education and Practice is an international, peerreviewed, open access journal that aims to present and publish research on Medical Education covering medical, dental, nursing and allied healthcare professional education. The journal covers undergraduate education, postgraduate training and continuing medical education

\section{Dovepress}

including emerging trends and innovative models linking education, research, and healthcare services. The manuscript management system is completely online and includes a very quick and fair peer-review system. Visit http://www.dovepress.com/testimonials.php to read real quotes from published authors. 